\title{
Analysis of water retention in soil horizons of two open trenches on a slope of Serra do Mar, Brazil, susceptible to landslides
}

\author{
Carolina V. Perdomo ${ }^{1, *}$, Lidiane C. Nogueira ${ }^{1}$, Miriam G. Miguel ${ }^{2}$, and Francisco S. B. Ladeira ${ }^{1}$ \\ ${ }^{1}$ Geoscience Institute, Geography Department, University of Campinas - UNICAMP, Brazil \\ ${ }^{2}$ School of Civil Engineering, Architecture and Urban Design, Infrastruture and Environment Department, University of Campinas - \\ UNICAMP, Brazil
}

\begin{abstract}
This research presents and analyzes the results of Soil Water Characteristic Curves (SWCC) for the soil horizons (A, B and C) of two different trenches (TR3 and TR7) opened along a slope located in the Serra da Mar mountain range, Brazil. Microaggregations were observed in soil horizons of both trenches, which changed the textural classification of the soils. TR7 showed more macropores than TR3, especially on horizon C. Unimodal SWCC were obtained for soils of the horizon A for both trenches. Instead, bimodal SWCC were obtained for soils of the deeper horizons (B and C). All soil horizons showed the phenomenon of hysteresis, and it's more expressive in the macroporosity part. In TR7 the water retention capacity is lower in B and C, facilitating the drainage, however, horizons B and C of TR3 presented greater water retention capacity for the same matric suction value. Depending on the intensity and duration of rainfall, the horizons $\mathrm{B}$ and $\mathrm{C}$ of both trenches may suffer a decrease of shear strength, without necessarily saturating. The A horizon of TR3 can undergo an erosive process for heavy and short rains.
\end{abstract}

\section{Introduction}

Serra do Mar is a mountainous formation that extends for $1500 \mathrm{~km}$ from the south to the southeast of Brazil coast. Landslides are the most frequent gravitational mass movements and occur naturally, and are often aggravated due to anthropic occupation. The average rainfall of Serra do Mar exceeds 3,300 $\mathrm{mm}$ /year and occasionally reaches $4,500 \mathrm{~mm} /$ year, with the highest total between October to March (spring and summer seasons) [1].

The main influence factor of landslides in the climatic and geological dynamics of Brazil is the rain ([2], [3]), which has the potential to trigger several destabilizing mechanisms, such as: raising the water level and generating percolation forces; temporary filling of cracks, cracks and / or structures in saprolitic soils and rocks, with the generation of hydrostatic pressures, and reducing the shear strength of soils, particularly, by the loss of matric suction.

Therefore, water behaviour in soil has important implications for defining the rupture mechanisms in the slopes of Serra do Mar, especially referring to positive water pressures in saturated soils or loss of soil suction and decrease with apparent cohesion in unsaturated soils [4].

One of the most effective analysis to understand how the water interacts in the soil profile is through the SoilWater characteristic Curve (SWCC), which represents the relation between moisture content and suction (osmotic, matric or total). Depending on the pore size distribution, the SWCC can be presented as unimodal, when there is the predominance of macropores, or bimodal, when there is the presence of both size of pore, with more micropores. SWCC can also be displayed on drying and wetting paths of the soil, however, in these two paths the SWCC do not coincide, presenting the hysteresis phenomenon. Stability analysis processes can have significant effects on the matric suction heads and the SWCC hysteresis [5]

Soils of Serra do Mar frequently are deep (reaching more than $2 \mathrm{~m}$ ) and quite weathered, due to high rainfall and thermal amplitude in the region. Consequently, they present expressive macroporosity due to intense leaching, which is part of the laterization processes in tropical areas.

The main objective of this study refers to characterization of the hydraulic properties of soil horizons of two open trenches opened in a slope of Serra do Mar, susceptible to landslides, and their implication in the stability with respect to landslides.

\section{Material and Method}

\subsection{Study area}

Santos is a city located in the coast of São Paulo state, southeastern Brazil. This city is placed between Atlantic Ocean and Serra do Mar. The study area includes Saboó and Chico de Paula hills belonging to Serra do Mar $\left(46^{\circ} 21^{\prime} 05^{\prime \prime} \mathrm{W}\right.$ and $\left.23^{\circ} 56^{\prime} 12^{\prime \prime} \mathrm{S}\right)$, covered by Atlantic Forest, however with dispersed anthropic occupation.

\footnotetext{
Corresponding author: caveper@hotmail.com
} 
1929, and later in 1956, when the precipitation reached the value of $373 \mathrm{~mm}$ in $24 \mathrm{~h}$ triggering 60 landslides almost simultaneously [1]

The biggest port in Brazil is located in Santos city, and because of this, it presents a different urban dynamic, with a lot of circulating trucks and many dock workers, the majority of them without social privileges. So, they occupy inappropriate areas, such as hillslopes, further enhancing the risks of landslides.

\subsection{Sampling and laboratory tests}

Two trenches (TR3 and TR7) were opened in different positions along a slope on a Saboó and Chico de Paula hills. TR3 is located on a little plateau, and TR7 on a board of landslides scar. A pedological description was performed defining specific soil horizons (A, B and C) for both trenches.

Disturbed soil samples were collected in each horizon, of two trenches and subjected to physical and geotechnical tests, such as: particle density [6], particlesize distribution [7], with and without the use of deflocculant in sedimentation phase, and liquid [8] and plasticity limits [9].

Six undisturbed samples were also collected in each horizon of two trenches, by the carefully setting of metal rings (diameter of $5 \mathrm{~cm}$ and height of $2 \mathrm{~cm}$ ), totaling 36 specimens (metal ring and soil inside). Physical indexes were determined for each specimen such as soil density [6], and gravimetric moisture content [10]. Dry density and porosity were change by physical correlations.

Soil-Water Characteristic Curve (SWCC), in two paths (wetting and drying), were obtained for the six specimens of three horizons (A, B and C) of two trenches (TR3 and TR7), using the filter paper method [11]. In each horizon, three specimens were subjected to wetting path and the other three to drying path. The filter paper used was Whatman $\mathrm{n}^{\circ} 42$, which the matric suction ( $\left.\Psi\right)$, in $\mathrm{kPa}$, is determinate by Chandler equations (Eq. 1 and 2), validated by prior calibration (Eq. 1 and 2). It is worth mentioning that filter paper has a matric suction measurement capacity from $3 \mathrm{kPa}$.

$$
\begin{aligned}
& \Psi=10^{\wedge}\left\{4.84-\left[0.0622 *\left(w_{p}<47 \%\right)\right]\right\} \\
& \Psi=10^{\wedge}\left\{6.05-\left[2.48 * \log \left(w_{p}>47 \%\right)\right]\right\}
\end{aligned}
$$

where: $\mathrm{w}_{\mathrm{p}}=$ gravimetric moisture content of the filter paper

The filter paper was kept in contact with the soil, to measure the matric suction, for 7 days, without exchange with the air and exposition to temperature, light and moisture.

All the unimodal SWCC were fitted by Van Genuchten model [12], represented by equation (Eq. 3)

$$
\theta=\theta_{\text {res }}+\left(\theta_{\text {sat }}-\theta_{\text {res }}\right) /\left[1+\left(\alpha^{*} \psi\right)^{n}\right]^{m}
$$

where: $\theta=$ volumetric moisture content $(\%), \theta_{\text {res }}=$ residual volumetric moisture content $(\%), \theta_{\text {sat }}=$ saturation volumetric moisture content $(\%), \alpha\left(\mathrm{kPa}^{-1}\right)=$ independent parameters associated with the air-entry value or air-outlet value, that is, their inverse values, $\mathrm{m}=$ independent parameters related to curve asymmetry, and $\mathrm{n}=$ independent parameters related to uniform pore distribution

Relation between volumetric and gravimetric moisture content of the soil is seen in Eq. 4.

$$
\theta=\frac{w \cdot \gamma_{d}}{\gamma_{w}}
$$

where: $\mathrm{w}=$ gravimetric moisture content, $\gamma_{\mathrm{d}}=$ dry density and $\gamma_{\mathrm{w}}=$ water density

When the SWCC presented bimodality, the equation (3) were applied separately to macroporosity and microporosity parts. The volumetric moisture content on the beginning of microporosity part was designated as $\theta \mathrm{i}$.

Additionally, specimens were trimmed from the undisturbed soil samples collected of the B and C horizons of two trenches and they were subjected to mercury intrusion porosimetry (MIP) tests. The equipment used was the Micromeritics Pore Sizer 9320, V2.04 porosimeter, with an average pore distribution range of $0.006 \mu \mathrm{m}$ to $300 \mu \mathrm{m}$. MIP test is applied to measure pores between $0.003 \mu \mathrm{m}$ to $400 \mu \mathrm{m}$, being more suitable $0.1 \mu \mathrm{m}$ to $100 \mu \mathrm{m}$.

\section{Results}

\subsection{Physical characterization}

Physical characterization obtained by disturbed soil samples is presented in Table 1. Table 2 shows the average values of the physical indexes obtained from the three specimens collected in each horizon of both trenches, using for each path (drying and wetting).

The only horizons that presented plasticity were horizons $\mathrm{B}$ and $\mathrm{C}$ of TR3. Horizon B showed the highest plasticity index (PI), due to the higher value of the liquid limit (LL), since the values of plastic limits (PL) are close. Porosity values were high, the minimum was close to $55 \%$. The TR3 horizon A showed higher porosity values than the other two horizons. In TR7, the porosity values of the three horizons were close.

The percentages of the granulometric fractions obtained in the particle-size distribution tests with (WD) and without (ND) the use of the deflocculant are shown in Table 3, for each horizon of two trenches.

Table 1. Physical characterization

\begin{tabular}{c|c|c|c|c|c}
\hline Trench-Horizon & W\% & LL & PL & PI & $\begin{array}{c}\gamma_{\mathrm{s}} \\
\left(\mathrm{g} / \mathrm{m}^{3}\right)\end{array}$ \\
\hline TR3-A & 43.44 & NP & NP & NP & 2.561 \\
TR3-B & 22.34 & 66.9 & 42.3 & 24.6 & 2.815 \\
TR3-C & 11.95 & 58.0 & 42.4 & 15.6 & 2.765 \\
\hline TR7-A & 20.97 & NP & NP & NP & 2.662 \\
TR7-B & 27.93 & NP & NP & NP & 2.759 \\
TR7-C & 29.71 & NP & NP & NP & 2.857 \\
\hline
\end{tabular}

W - Field moisture content: LL - Liquid limit: PL - Plastic limit: PI - Plasticity Index: $\gamma_{\mathrm{s}}-$ Particle density, NP - NonPlastic 
When the deflocculant was used, the TR3 horizons were classified as sandy-clay silts, with a higher percentage of the sand fraction on horizon $\mathrm{A}$ and practically the same percentage of the clay fraction for the three horizons. However, without the use of the deflocculant, horizon A of TR3 was classified as sand and horizons $\mathrm{B}$ and $\mathrm{C}$ were classified as silty sands.

Table 2. Physical indexes of the specimens

\begin{tabular}{c|c|c|c}
\hline \multirow{2}{*}{ Trench-Horizon } & \multicolumn{3}{|c}{ Drying path } \\
\cline { 2 - 4 } & $\mathrm{w}(\%)$ & $\gamma_{\mathrm{d}}\left(\mathrm{g} / \mathrm{m}^{3}\right)$ & $\mathrm{n}(\%)$ \\
\hline TR3-A & 54.65 & 0.877 & 65.76 \\
TR3-B & 37.66 & 1.166 & 58.42 \\
TR3-C & 33.90 & 1.253 & 54.67 \\
\hline TR7-A & 28.77 & 1.115 & 58.10 \\
TR7-B & 34.92 & 1.116 & 59.89 \\
TR7-C & 22.75 & 1.211 & 57.62 \\
\hline \multirow{3}{*}{ Trench-Horizon } & Wetting path \\
\cline { 2 - 4 } & 24.75 & $\gamma_{\mathrm{d}}\left(\mathrm{g} / \mathrm{m}^{3}\right)$ & $\mathrm{n}(\%)$ \\
\hline TR3-A & 17.94 & 1.840 & 67.19 \\
TR3-B & 14.29 & 1.170 & 55.00 \\
TR3-C & 4.69 & 0.999 & 62.48 \\
\hline TR7-A & 30.17 & 1.061 & 61.53 \\
TR7-B & 22.04 & 1.186 & 58.49 \\
\hline
\end{tabular}

$\mathrm{w}-$ gravimetric moisture content; $\gamma_{\mathrm{d}}$ - dry density; $\mathrm{n}$ - porosity.

Table 3. Percentages of granulometric fractions with (WD) and without (ND) deflocculant

\begin{tabular}{c|c|c|c|c|c|c}
\hline \multirow{2}{*}{$\begin{array}{c}\text { Trench/ } \\
\text { Horizon }\end{array}$} & \multicolumn{2}{|c|}{ Sand (\%) } & \multicolumn{2}{c|}{ Silt (\%) } & \multicolumn{2}{c}{ Clay (\%) } \\
\cline { 2 - 7 } & WD & ND & WD & ND & WD & ND \\
\hline TR3 -A & 45.4 & 95.1 & 27.6 & 4.9 & 27.0 & 0 \\
TR3 -B & 31.7 & 56.3 & 40.9 & 43.7 & 27.4 & 0 \\
TR3 - C & 33.5 & 50.9 & 39.5 & 49.1 & 27.1 & 0 \\
\hline TR7 -A & 60.5 & 74.9 & 27.1 & 25.1 & 12.3 & 0 \\
TR7 -B & 40.7 & 53.3 & 37.8 & 46.7 & 21.5 & 0 \\
TR7 -C & 48.5 & 57.4 & 45.5 & 42.6 & 6.0 & 0 \\
\hline
\end{tabular}

Considering TR7, with the use of the deflocculant, horizon A was classified as silty-clay sand, horizon B as sandy-clay silt and $\mathrm{C}$ as sandy silt. Without the use of the deflocculant, the three horizons of TR7 were classified as silty sands, with a percentage of the larger sand fraction for horizon A.

The percentage of clay fraction for all horizons of the two trenches was zero when the deflocculant was not used. This shows that this fraction is naturally aggregated in the field, forming lumps with diameters referring to the silt and sand fractions.

The textural difference presented by the soil horizons of the two trenches, with and without the use of a deflocculant, demonstrates the microaggregation of these soils, the result of intense pedogenetic processes, particularly leaching, which in a tropical environment, with slightly acid rainwater, eliminates the bases of the soil profile and maintains cementing agents, such as iron and aluminum oxides and hydroxides. Microaggregation interferes with the water behavior of soil horizons, because in the field, the soil has a granular texture, which facilitates drainage [13].

The values of consistency limits (Table 1) corroborate the textures obtained with the use of deflocculant, since the consistency tests are carried out with undisturbed samples and passed through the $0.42 \mathrm{~mm}$ diameter sieve (\# 40). The horizons with the highest percentage of the sand fraction, that is, horizon A of both trenches and horizons $\mathrm{B}$ and $\mathrm{C}$ of TR7, were classified as non-plastic. Plasticity is observed only in horizons B and C of TR3, with a higher percentage of the fine fraction (silt to clay), in tests with deflocculant (Table 2).

\subsection{Porosimetry}

Curves of Log differencial volume versus pore diameter are presented in Figure 1 for $\mathrm{B}$ and $\mathrm{C}$ horizons for both trenches (TR3 and TR7). These curves refer to the microaggregated structure, since this test uses undisturbed soil samples.

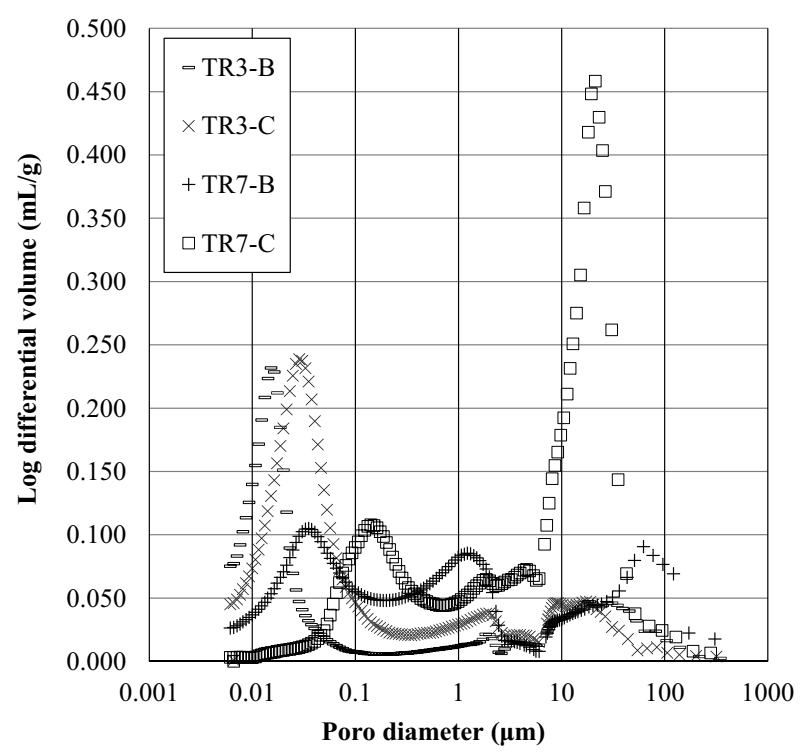

Fig. 1. Log differential volume versus pore diameter for B and $\mathrm{C}$ horizons of TR3 and TR7

Horizons $\mathrm{B}$ and $\mathrm{C}$ of TR 3 presented a pore distribution with predominance of the micropores between $0.015 \mu \mathrm{m}$ and $0.03 \mu \mathrm{m}$, respectively. The macropores had less expressiveness, with predominance of $13 \mu \mathrm{m}$, for both horizons, despite the percentage of the sand fraction in the microaggregated structure for horizon $\mathrm{B}$ was higher than horizon $\mathrm{C}$ (Table 3 ). The values of porosity for $\mathrm{B}$ and $\mathrm{C}$ horizons varied between 54.7 to $58.4 \%$ (Table 2).

Horizon B of TR7 presented a better uniformity of pore distribution, with little predominance of pores with diameters of $0.04 \mu \mathrm{m}, 1.5 \mu \mathrm{m}$ and $62 \mu \mathrm{m}$. Nonetheless, horizon C of TR7 showed expressive predominance of the macropores of $21 \mu \mathrm{m}$ and, with less expressiveness, micropores of in $0.15 \mu \mathrm{m}$. Despite values of porosity of Horizons B and C of TR7 were practically similar (Table 2 ), the distributions of pores on these horizons were totally different and the microaggregation was more expressive in horizon B (Table 3). 


\subsection{Soil-Water Characteristic Curves (SWCC)}

Experimental and fitting SWCC obtained for A, B, and C horizons of TR3 and TR7 are presented in Figures 2 and 3 , respectively, for both paths (drying and wetting). The fitting parameters, by van Genuchten model [12], are shown in Table 4, for TR3, and in Table 5, for TR7.

\subsubsection{SWCC for TR3}

SWCC of horizon A (16cm thickness) of TR3 were unimodal and presented significant hysteresis. The shapes of the curves are typical of sands, which is in accordance with the microaggregated texture classification (sand) presented by this horizon, that is, the texture obtained without the use of deflocculant (Table 3). The values of air-entry $(5 \mathrm{kPa})$, in the drying path, and air outlet $(2.2 \mathrm{kPa})$, in the wetting path, are considered low, also typical of the sandy texture.

Horizons B $(150 \mathrm{~cm}$ thickness) and C $(160 \mathrm{~cm}$ thickness) of TR3 showed very similar SWCC, presenting bimodal shape, according to pore distribution curves (Figure 1) and microaggregated textural classification (silty sand). The hysteresis was less expressive than the horizon A, with predominance in the part referring to macroporosity. The values of air-entry and air outlet in the macropores were considered low, ranging from 2.5 to 5 $\mathrm{kPa}$. In the part referring to microporosity, these values are high, between 330 and $3,300 \mathrm{kPa}$ (Table 4), suggesting the interference of the clay fraction (Table 2) with relative colloidal activity (Table 1). Only horizon B showed swelling during saturation, and shrinkage when dried.

\subsubsection{SWCC for TR7}

The three horizons of TR7 presented the phenomenon of hysteresis in the section referring to macroporosity. Only the SWCC of horizon A (10 cm thickness) presented itself as unimodal. SWCC of horizons B (50 cm thickness) and C (55cm thickness) were presented as bimodal, which is in agreement with the results of the porosimetry tests (Figure 1), although the bimodality is more expressive for the $\mathrm{C}$ horizon, with a higher frequency of macropores $(21 \mu \mathrm{m})$.

As in TR3, horizon A of TR7 shows SWCC shapes typical of sands, according to the textural classification obtained considering the microaggregation (silty sand) and to consistence tests, classified as non-plastic (Table 1). Low values of air entry ( $8 \mathrm{kPa})$, in the drying path, and air outlet $(2 \mathrm{kPa})$, in the wetting path, were also found (Table 5).

Horizon C showed practically the same porosity value and same microaggregated textural classification (silty sand) as horizon B, however, its pore distribution is not uniform as shown for horizon $\mathrm{B}$, which indicated different SWCC shapes.

Values of air entry and air outlet in the macroporosity part were between 2.5 and $5 \mathrm{kPa}$ for horizons B and C. In the microporosity part, these values varied from 20 to 110 $\mathrm{kPa}$, with the lowest value referring to horizon $\mathrm{B}$ in the drying path (Table 5). None of the horizons showed swelling or shrinkage during the respective saturation and drying procedures.

\subsubsection{Hydraulic behavior of TR3 and TR7}

SWCC for drying and wetting paths for TR3 and for TR7 are presented in Figure 4 and 5, respectively.

The drying paths of the SWCC of TR3 (Fig. 4) crossed at $30 \mathrm{kPa}$ and $35 \%$. Coincidentally, the value of $30 \mathrm{kPa}$ is considered the reference to determine the field capacity in sandy soils, whose value represents the maximum amount of water retained in the capillaries of the soil matric after saturation and gravitational drainage. In this case, this value for the three horizons of TR 3 was $35 \%$.
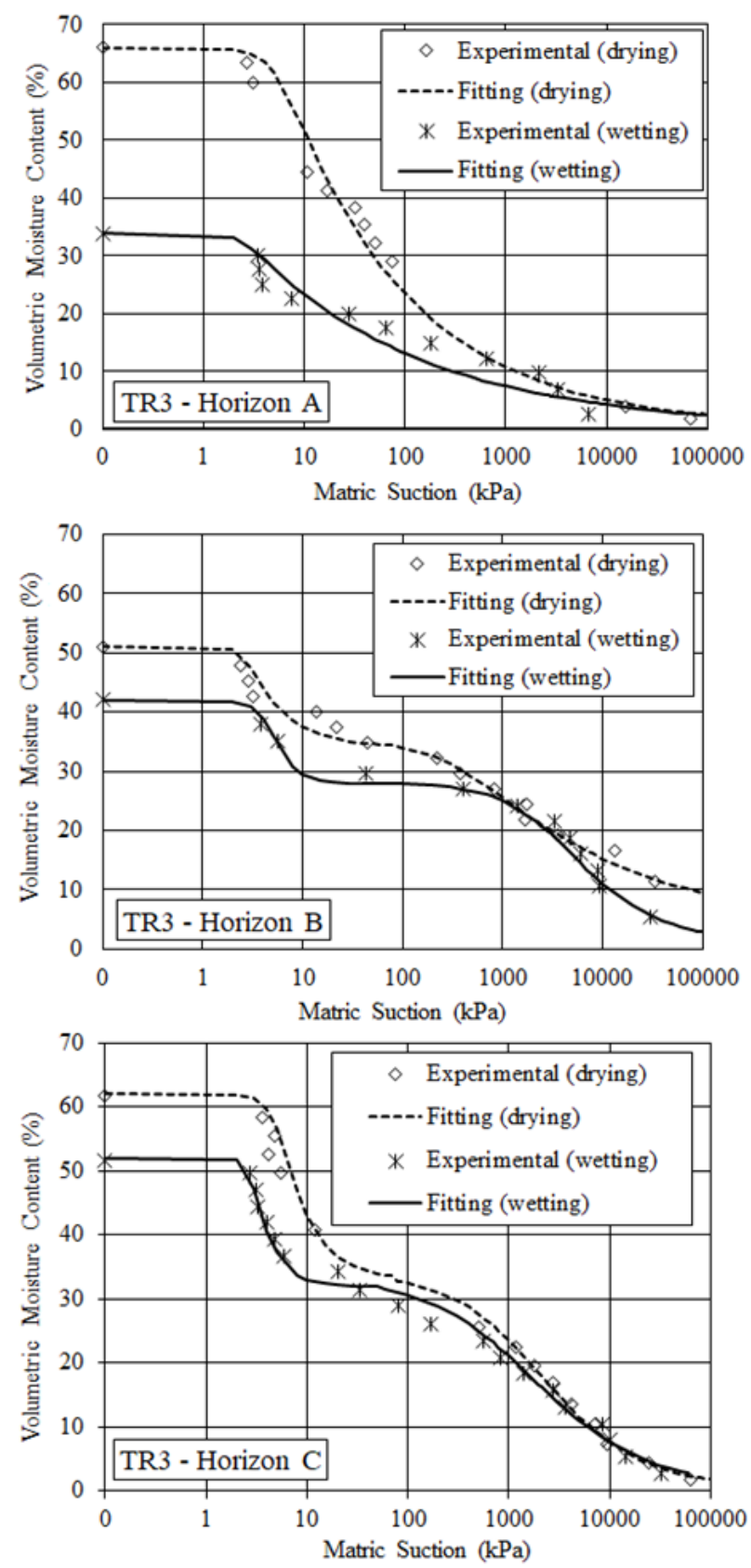

Fig. 2. SWCC for drying and wetting paths for horizons A, B and $\mathrm{C}$ of TR3 
For smaller matric suctions, horizon $\mathrm{A}$ is able to retain greater moisture, followed by horizon $\mathrm{C}$ and horizon $\mathrm{B}$, considering the same suction value. For higher suction values, there is an inversion, that is, drainage is easier on horizon A, followed by $\mathrm{B}$ and $\mathrm{C}$, although in the stretch between 30 and $1,000 \mathrm{kPa}$, the SWCC of horizons $\mathrm{B}$ and $\mathrm{C}$ practically overlap. From the value of $30,000 \mathrm{kPa}$ to $100,000 \mathrm{kPa}$ (last measurement) the SWCC from horizons $\mathrm{A}$ and $\mathrm{C}$ also overlap. In the wetting path, horizon $\mathrm{A}$ has greater difficulty in retaining moisture than horizons $\mathrm{B}$ and $\mathrm{C}$ for any suction value.
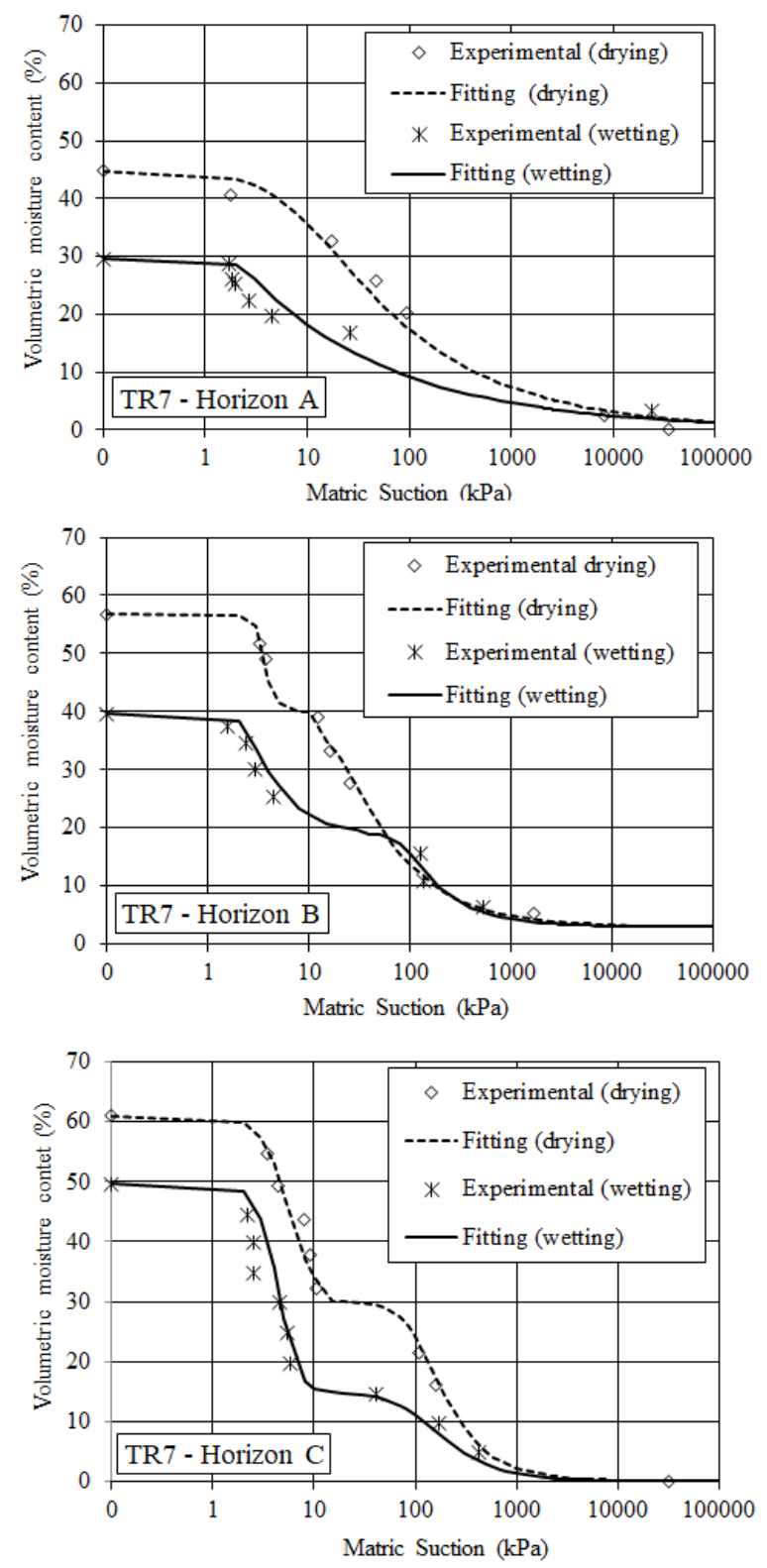

Fig. 3. SWCC for drying and wetting paths for horizons A, B and $\mathrm{C}$ of TR7

Horizons B and C of TR3 during wetting showed SWCC very close down to $5 \mathrm{kPa}$ matric suction (greatest variation in moisture is $6 \%$ ). For lower suction values, the SWCC distance themselves (more separated), with the B horizon already very close to saturation, with a lower moisture value.
The value of the saturated volumetric moisture $\left(\theta_{\text {sat }}\right)$ is the value of the total soil porosity. In the drying path, the $\theta_{\text {sat }}$ values (Table 4$)$ were close $(+/-13 \%$ generally, except for TR7 A, about 23\%) to the porosity values (Table 2) for the three horizons, that is, the specimens were able, during the back pressure saturation, to fill a large part of the pores with water. However, in the wetting path, the $\theta$ sat values were lower, confirming the difficulty of these horizons, especially the $\mathrm{A}$, in reaching saturation when wetted, due to the difficulty in expelling the air from the macropores.

Table 4. Fitting parameters for TR3

\begin{tabular}{|c|c|c|c|c|c|}
\hline \multicolumn{6}{|c|}{ Macroporosity } \\
\hline \multirow{2}{*}{ TR3 } & \multicolumn{5}{|c|}{ Drying } \\
\hline & $\alpha\left(\mathrm{kPa}^{-1}\right)$ & $\mathrm{n}$ & $\mathrm{m}$ & $\theta_{\text {sat }}(\%)$ & $\theta_{\text {res }}(\%)$ \\
\hline $\mathrm{A}$ & 0.20 & 3.5 & 0.10 & 66.0 & 0.5 \\
\hline $\mathrm{B}$ & 0.40 & 8.0 & 0.14 & 51.0 & 34.0 \\
\hline $\mathrm{C}$ & 0.20 & 5.0 & 0.30 & 62.0 & 33.0 \\
\hline \multirow{2}{*}{ TR3 } & \multicolumn{5}{|c|}{ Wetting } \\
\hline & $\alpha\left(\mathrm{kPa}^{-1}\right)$ & $\mathrm{n}$ & $\mathrm{m}$ & $\theta_{\text {sat }}(\%)$ & $\theta_{\text {res }}(\%)$ \\
\hline $\mathrm{A}$ & 0.45 & 5.00 & 0.05 & 34.0 & 0.1 \\
\hline $\mathrm{B}$ & 0.20 & 4.25 & 0.76 & 42.0 & 28.0 \\
\hline $\mathrm{C}$ & 0.35 & 8.00 & 0.30 & 52.0 & 32.0 \\
\hline \multicolumn{6}{|c|}{ Microporosity } \\
\hline \multirow{2}{*}{ TR3 } & \multicolumn{5}{|c|}{ Drying } \\
\hline & $\alpha\left(\mathrm{kPa}^{-1}\right)$ & $\mathrm{n}$ & $\mathrm{m}$ & $\theta_{\mathrm{i}}(\%)$ & $\theta_{\text {res }}(\%)$ \\
\hline $\mathrm{A}$ & - & - & - & - & - \\
\hline $\mathrm{B}$ & 0.0030 & 1.4 & 0.2 & 35.0 & 3.0 \\
\hline $\mathrm{C}$ & 0.0006 & 1.0 & 0.8 & 34.0 & 0.5 \\
\hline \multirow{2}{*}{ TR3 } & \multicolumn{5}{|c|}{ Wetting } \\
\hline & $\alpha\left(\mathrm{kPa}^{-1}\right)$ & $\mathrm{n}$ & $\mathrm{m}$ & $\theta_{\mathrm{i}}(\%)$ & $\theta_{\text {res }}(\%)$ \\
\hline A & - & - & - & - & - \\
\hline $\mathrm{B}$ & 0.0003 & 1.3 & 0.6 & 28.0 & 1.0 \\
\hline $\mathrm{C}$ & 0.0009 & 0.9 & 0.7 & 33.0 & 0.1 \\
\hline
\end{tabular}

Table 5. Fitting parameters for TR7

\begin{tabular}{|c|c|c|c|c|c|}
\hline \multicolumn{6}{|c|}{ Macroporosity } \\
\hline \multirow{2}{*}{ TR7 } & \multicolumn{5}{|c|}{ Drying } \\
\hline & $\alpha\left(\mathrm{kPa}^{-1}\right)$ & $\mathrm{n}$ & $\mathrm{m}$ & $\theta_{\text {sat }}(\%)$ & $\theta_{\text {res }}(\%)$ \\
\hline A & 0.12 & 1.38 & 0.28 & 44.9 & 0.1 \\
\hline B & 0.30 & 12.00 & 0.50 & 57.0 & 40.0 \\
\hline $\mathrm{C}$ & 0.20 & 3.50 & 0.80 & 61.0 & 30.0 \\
\hline \multirow{2}{*}{ TR7 } & \multicolumn{5}{|c|}{ Wetting } \\
\hline & $\alpha\left(\mathrm{kPa}^{-1}\right)$ & $\mathrm{n}$ & $\mathrm{m}$ & $\theta_{\text {sat }}(\%)$ & $\theta_{\text {res }}(\%)$ \\
\hline $\mathrm{A}$ & 0.5 & 6.0 & 0.05 & 29.61 & 0.1 \\
\hline $\mathrm{B}$ & 0.4 & 3.5 & 0.40 & 39.69 & 19.0 \\
\hline $\mathrm{C}$ & 0.2 & 4.0 & 1.50 & 49.66 & 15.0 \\
\hline \multicolumn{6}{|c|}{ Microporosity } \\
\hline \multirow{2}{*}{ TR7 } & \multicolumn{5}{|c|}{ Drying } \\
\hline & $\alpha\left(\mathrm{kPa}^{-1}\right)$ & $\mathrm{n}$ & $\mathrm{m}$ & $\theta_{\mathrm{i}}(\%)$ & $\theta_{\text {res }}(\%)$ \\
\hline $\mathrm{A}$ & - & - & - & - & - \\
\hline $\mathrm{B}$ & 0.050 & 2.2 & 0.35 & 40.0 & 3.0 \\
\hline $\mathrm{C}$ & 0.009 & 3.0 & 0.40 & 30.0 & 0.1 \\
\hline \multirow{2}{*}{ TR7 } & \multicolumn{5}{|c|}{ Wetting } \\
\hline & $\alpha\left(\mathrm{kPa}^{-1}\right)$ & $\mathrm{n}$ & $\mathrm{m}$ & $\theta_{\mathrm{i}}(\%)$ & $\theta_{\text {res }}(\%)$ \\
\hline $\mathrm{A}$ & - & - & - & - & - \\
\hline $\mathrm{B}$ & 0.012 & 5.0 & 0.2 & 19.0 & 3.0 \\
\hline $\mathrm{C}$ & 0.010 & 2.0 & 0.6 & 15.0 & 0.1 \\
\hline
\end{tabular}

The horizons of TR7 in the drying path showed SWCC that intersect in the matric suction value of $30 \mathrm{kPa}$ and $30 \%$ volumetric moisture. These horizons were classified 
as silty sands representing the microaggregate structure, therefore, the volumetric moisture content of $30 \%$ represents the field capacity of the soils of these horizons.

Values between $8 \mathrm{kPa}$ and $30 \mathrm{kPa}$ on the drying path the SWCC practically overlap. For values less than $8 \mathrm{kPa}$, horizon $\mathrm{C}$ was able to retain more moisture, followed by $\mathrm{B}$ and $\mathrm{A}$, considering the same matric suction value. After $30 \mathrm{kPa}$, the SWCC showed practically the same behavior, with the exception of the stretch between 30 and $400 \mathrm{kPa}$, who is SWCC from the $\mathrm{C}$ horizon indicated that it was able to retain a little more moisture during drainage. The horizons of the TR7 in the drying path showed SWCC that intersect in the matric suction value of $30 \mathrm{kPa}$ and $30 \%$ volumetric moisture. These horizons were classified as silty sands representing the microaggregated structure, therefore, the volumetric moisture content of $30 \%$ represents the field capacity of the soils of these horizons.
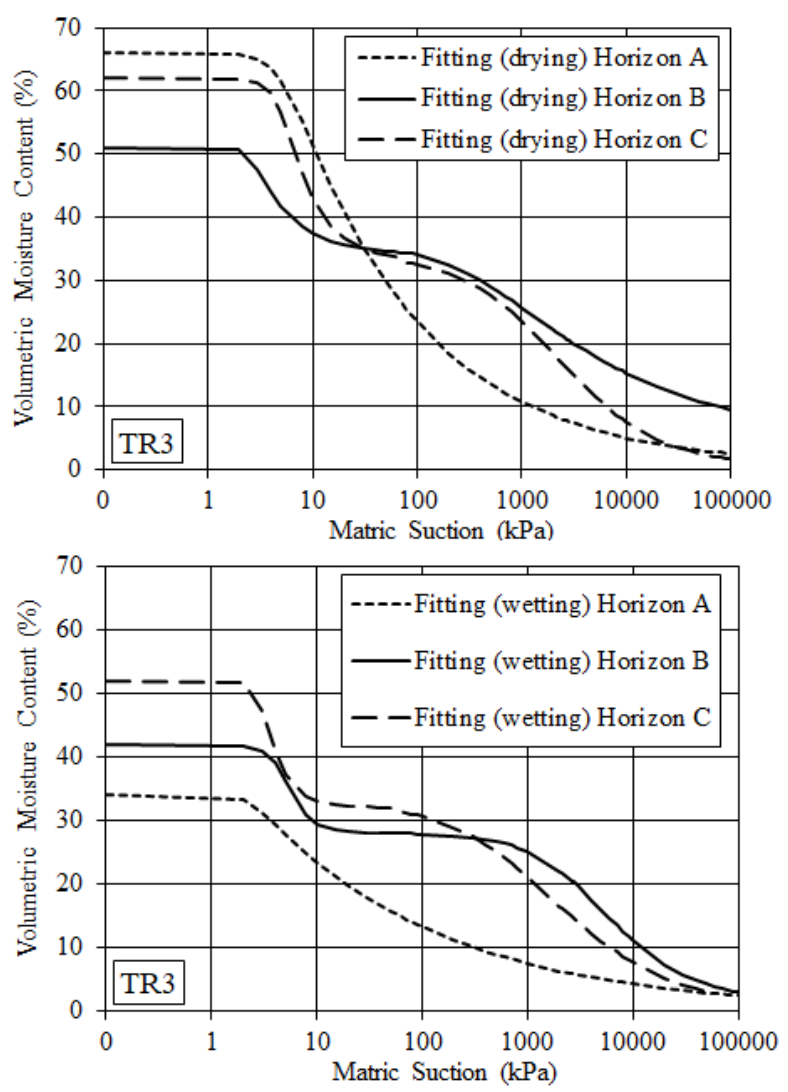

Fig. 4. SWCC for drying and wetting paths for TR3

Upon wetting, from the highest measured suction value $(100,000 \mathrm{kPa})$ to $300 \mathrm{kPa}$, the $\mathrm{SWCC}$ showed practically the same behavior. Between approximately $300 \mathrm{kPa}$ and $5 \mathrm{kPa}$, horizon $\mathrm{B}$ showed less difficulty in retaining moisture.

The specimens used to obtain the SWCC for the three horizons of the TR7 in the wetting and drying paths were unable to reach the volumetric moisture saturated by back pressure, as the values were lower than those of porosity. The presence of a predominance of macropores, demonstrated for horizons $\mathrm{B}$ and $\mathrm{C}$ in the results of porosimetry tests (Figure 1), may explain this fact.

Considering two current types of precipitation in Serra do Mar as being, the first represented by light and prolonged rains, and the second by heavy and fast rains, it is possible to indicate some water behaviors for TR3 and TR7.

During the light and prolonged rains, the A horizon of TR3 will allow water to infiltrate, as it has high porosity, but will have difficulty retaining this moisture. When this horizon reaches the field capacity, all the rainwater that still infiltrates will be drained to horizon B, which has a greater retention capacity. Since the rain is light, horizon $\mathrm{B}$ is able to hold this water slowly without horizon A saturating. With horizon B reaching the field capacity, it will start draining the infiltrated surplus to horizon $\mathrm{C}$ which will behave very similarly to B (Figure 4). Considering that below the $\mathrm{C}$ horizon, the rock has a very low infiltration rate, the saturation of the horizons may occur from the bottom upwards, that is, starting at $\mathrm{C}$ to $\mathrm{A}$. If the rains cease before, horizons $\mathrm{B}$ and $\mathrm{C}$ will be able to remain both in the field capacity, or at least the $\mathrm{B}$ horizon. The increase in moisture, even without reaching saturation, leads to a decrease in the shear strength of soils [14], these rains may destabilize the slope, in the part represented by TR3, with possible breaks in the B and / or C horizon.
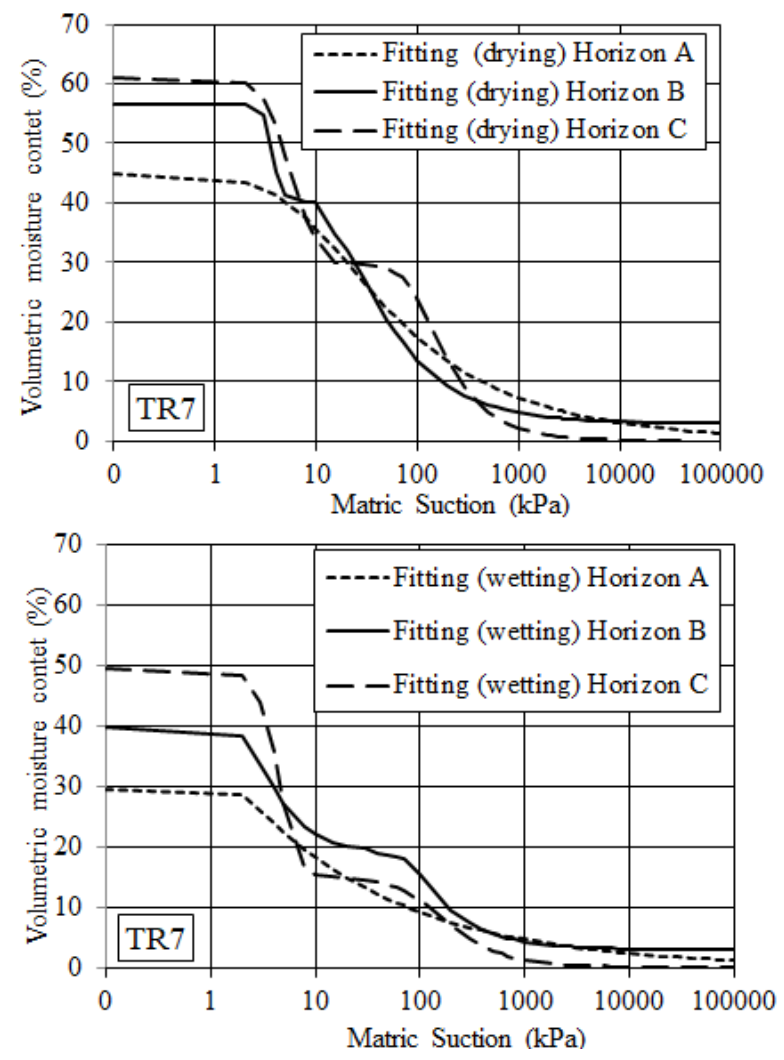

Fig. 5. SWCC for drying and wetting paths for TR7

In the case of TR7, the water retention capacity of horizons $\mathrm{B}$ and $\mathrm{C}$ is lower, facilitating the drainage of excess rainwater to the underlying horizon. The saturation of the horizons, however, will be hampered by the high porosity of these horizons, mainly the macro. Thus, destabilization will probably occur by decreasing the shear strength of these horizons B or C with increasing moisture content, without reaching saturation [15]. 
Heavy and short-term rains may saturate horizon A of TR3, since horizon $\mathrm{B}$ is capable of retaining greater moisture, the amount of water that infiltrates $A$ is greater than the amount that infiltrates B, with the surplus stored in A. Being very porous, but not very thick, horizon A will be subjected to percolation forces parallel to the slope surface and with the same inclination, which may result in an erosive process of this horizon, exposing horizon B.

TR7 did not show this difference in water retention between the horizons at the beginning of the wetting path, which indicates that the drainage of excess infiltrated water will occur more easily from one horizon to the other. As these rains are of great intensity, saturation may occur from horizon $\mathrm{C}$ to $\mathrm{A}$, considering that the rock underlying $\mathrm{C}$ has a very low infiltration rate. However, before reaching saturation, the destabilization of the slope in the TR7 region may be represented by the loss of shear strength of the soil by moistening in B or C.

\section{Conclusion}

Horizons A for both trenches showed less water retention capacity and hysteresis with more expressivity, due to sandy texture and high porosity.

Horizons $\mathrm{B}$ and $\mathrm{C}$ of TR3 were the only ones to present plasticity and the most expressive microporosity. Because of this they showed greater water retention capacity for the same matric suction value than TR7 horizons $\mathrm{B}$ and $\mathrm{C}$. These were non-plastic and had a more pronounced macroporosity.

These different hydraulic behaviors were discussed for two kind of the rainfall, typical of Serra do Mar. Light and prolonged rains may destabilize the slope, with possible ruptures in the $\mathrm{B}$ and / or $\mathrm{C}$ horizon, of two trenches, due to increase of moisture and, consequently, decrease of shear strength.

Heavy and short-term rains may saturate horizon A of TR3, since horizon B is able to retain greater moisture, which may cause percolation forces parallel to the slope surface and with the same inclination in an erosive process of Horizon A. For TR7, the drainage of excess infiltrated water may occur more easily from one horizon to the other, so saturation may occur from horizon $\mathrm{C}$ to $\mathrm{A}$, considering that the rock bed has a very low infiltration rate. However, before reaching saturation, the destabilization may be represented by the loss of shear strength of the soil by moistening in B or $\mathrm{C}$.

\section{References}

1. T.D. Nery \& B.C. Vieira. (2015). Susceptibility to shallow landslides in a drainage basin in the Serra do Mar. São Paulo. Brazil. predicted using the SINMAP mathematical model. Bull. Eng. Geol. Environ. 74, 369-378.

2. K.C. Ma, Y.C. Tan, C.H. Chen. (2011). The influence of water retention curve hysteresis on the stability of unsaturated soil slopes. Hydrol. Process. 25, 35633574 .
3. M.A. Kanji, P.T. Cruz, F. Massad. (2008). Debris Flow Affecting the Cubatão Oil Refinary, Brazil. Landslides. 5, 71-82.

4. M. E. Seluchi, S. C. Chou, M. Gramani (2011). A case study of winter heavy rainfall event over Serra do Mar in Brazil. Geofísica International. 50: 1, 4156.

5. N.F. Fernandes, R.F. Guimarães, R.A.T. Gomes, B.C. Vieira, D.R. Montgomery, H. Greenberg. (2004). Topographic controls of landslides in Rio de Janeiro: field evidence and modeling. Catena. 5, 163181.

6. ABNT - Associação Brasileira de Normas Técnicas - Determinação da massa específica, da massa específica aparente e da absorção de água. NBR 6458. 2016. (in portuguese).

7. ABNT - Associação Brasileira de Normas Técnicas - Análise Granulométrica. NBR 7181. 2016. (in portuguese).

8. ABNT - Associação Brasileira de Normas Técnicas - Determinação do limite de liquidez. NBR 6459. 2016. (in portuguese).

9. ABNT - Associação Brasileira de Normas Técnicas - Determinação do limite de plasticidade. NBR 7180. 2016. (in portuguese).

10. ABNT - Associação Brasileira de Normas Técnicas - Preparação para ensaios de compactação e ensaios de caracterização. NBR 6457. 2016. (in portuguese).

11. ASTM, American Society for Testing Materials. ASTM-D 5298-03. 2003. Standard test method for measurement of soil potential (suction) using filter paper. West Conshohocken, PA.

12. M.T. van Genuchten (1980). A Closed Form Equation for Predicting the Hydraulic Conductivity of Unsaturated Soils. Proc. Sci. Soc. Am. 44: 5, 892898.

13. A. Satyanaga, H. Rahardjo, E.C. Leong, J.Y. Wang. (2013). Water Characteristic Curve of Soil with Bimodal Grain-Size Distribution. Computers and Geotechnics. 48, 51-61.

14. M. Suradi. (2015). Rainfall induced failures on natural slopes in tropical regions. $\mathrm{PhD}$ tesis of the University of Western Australia. School of Civil. Environmental and Mining Enginnering.

15. C.Y. Liu, C.Y. Ku, J.E. Xiao, C.C. Huang, S.M. Hsu. (2017). Numerical Modeling of unsaturated layered soil for rainfall-induced shallow landslides. Journal of Environmental Engineering and Landscape Management. 25: 04, 329-341. 